\section{A rare case of intussusception diagnosed by ultrasonography: lipoma of the colon}

\author{
Bahjat Barakat, ${ }^{1}$ Raffaele Pezzilli ${ }^{2}$ \\ 'Department of Emergency, S. Orsola- \\ Malpighi University Hospital, Bologna; \\ ${ }^{2}$ Department of Digestive System \\ S. Orsola-Malpighi University Hospital, \\ Bologna, Italy
}

An 85 year-old female patient was admitted to the Emergency Room because of persistent non-specific abdominal pain of 10 days duration associated to nausea and sometimes vomiting. On admission on Emergency Room, the abdomen was enlarged, without signs of ascites, and pain on palpation midway between

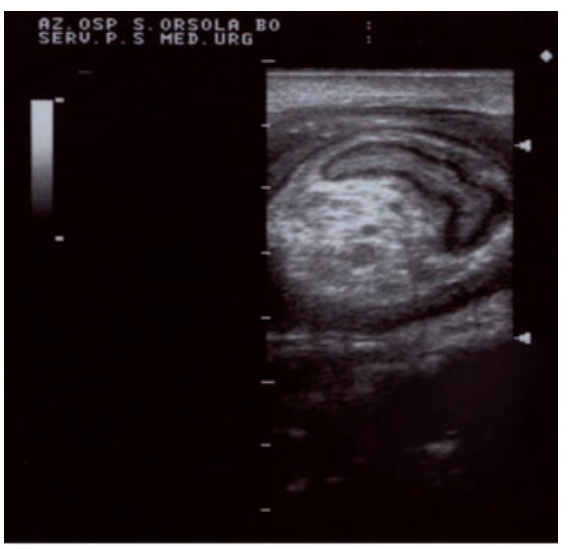

Figure 1. Transverse ultrasonographic image of the intussusception. Note the hypoechoic layer of edematous bowel wall with echogenic layers, known as the bull'seye or target signs.

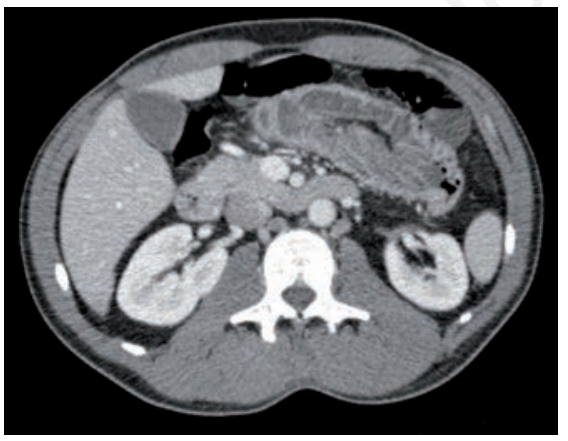

Figure 2. Contrast-enhanced longitudinal computed tomography scan showing inhomogeneous soft tissue mass containing low and high-density structures and producing a layered pattern sausage-shaped. umbilicus and right inferior quadrant; patient had no rebound tenderness in all abdominal. Laboratory examination revealed an increase of white blood cells $(13,500 \mathrm{mmc})$ : renal, hepatic and coagulation parameters were within the normal limits. A bed ultrasound (US) examination showed an imaging compatible with colic intussusception; in fact, a hypoechoic layer of edematous bowel wall with echogenic layers (bull's-eye signs) was detected (Figure 1). To better define the US picture, a computed tomography scan was carried out, showing an inhomogeneous soft tissue mass containing low and high-density structures, producing a layered pattern sausage-shaped (Figure 2). The patient was operated and during the operation were found signs of invagination of the wall (Figure 3). A left colic resection was carried out and termino-terminal anastomosis was made. The pathological examination of the resected specimen showed the presence of a small lipoma of the colic wall (Figure 4). Intussusception, as a cause of intestinal obstruction in adult, is rare entity and it requires early diagnosis and surgical

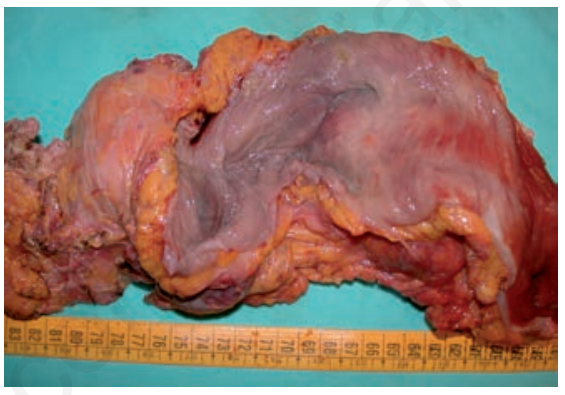

Figure 3. Surgical specimen showing signs of invagination of the wall, which consequently has become tortuous and malacic.

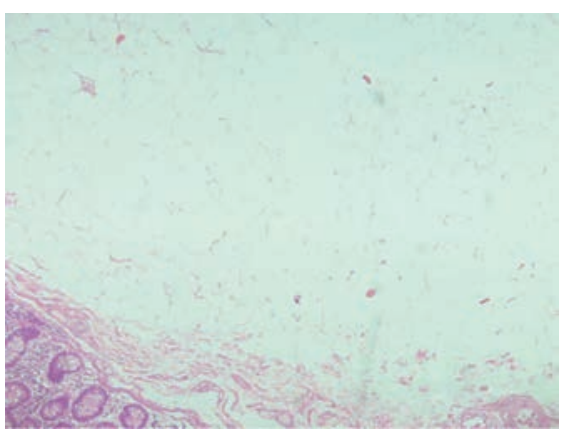

Figure 4. Pathological examination of the resected specimen showing the presence of a small lipoma of the colic wall.
Correspondence: Raffaele Pezzilli, Department of Digestive System, S. Orsola-Malpighi University Hospital, via Massarenti 9, 40138 Bologna, Italy. Tel. +39.051.2144148 - Fax: +39.051.2144148.

E-mail: raffaele.pezzilli@aosp.bo.it

Conflict of interest: the authors declare no potential conflict of interest.

Key words: adult intussusception, sub-acute symptoms, chronic symptoms, lipoma, resection.

Received for publication: 5 December 2014. Accepted for publication: 3 February 2015.

This work is licensed under a Creative Commons Attribution 3.0 License (by-nc 3.0).

(C) Copyright B. Barakat and R. Pezzilli et al., 2015 Licensee PAGEPress, Italy

Emergency Care Journal 2015; 11:4884

doi:10.4081/ecj.2015.4884

intervention..$^{1-3}$ Contrary to the management of intussusception in children -about $80 \%$ of whom is treated effectively by pneumatic or hydrostatic reduction, in adults treatment is mainly surgical. ${ }^{4,5}$ It should be underlined that the treatment of adult intussusception is not universally agreed upon and all authors suggest that laparotomy is mandatory in order to identify the pathological lesion causing it..$^{3-5}$ In our case a lipoma was found on the pathological specimen. It is also noticeable how ultrasound imaging is a useful first-line approach for the diagnosis of intussusception in adults.

\section{References}

1. Azar T, Berger DL. Adult intussusception. Ann Surg 1997;226:134-8.

2. Khan MN, Agrawal A, Strauss P. Ileocolic intussusception. A rare cause of acute intestinal obstruction in adults. Case report and literature review. World $\mathrm{J}$ Emerg Surg 2008;3:26.

3. Ongom PA, Opio CK, Kijjambu SC. Presentation, aetiology and treatment of adult intussusception in a tertiary SubSaharan hospital: a 10-year retrospective study. BMC Gastroenterol 2014; 14:86.

4. Begos DG, Sandor A, Modlin IM. The diagnosis and management of adult intussusception. Am J Surg 1997;173:88-94.

5. Reijnen HAM, DeBoer HHM. Diagnosis and treatment of adult intussusception. Am J Surg 1989;158:25-8. 